\title{
Aproveitamento de resíduos finos de rochas ornamentais na fabricação de ladrilho hidráulico piso tátil para a orientação de deficientes visuais
}

Utilization of fine residues of ornamental rocks in the manufacture of hydraulic tactile floor tile for the guidance of visually impaired people

\author{
Telma Ellen Drumond Ferreira, ${ }^{1, *}$; Eugenio Eustáquio Ferreira ${ }^{2}$; Marinna Beatrys Dias Souza \\ Chaves $^{3}$; Paulo Henrique Gonçalves ${ }^{4}$ \\ 1, 2, 3, 4 Universidade do Estado de Minas Gerais, João Monlevade, MG, Brasil. \\ *telmaellen@hotmail.com
}

\begin{abstract}
Resumo
As rochas ornamentais são classificadas em granitos e mármores, normalmente extraídas em pedreiras, na forma de blocos, e posteriormente destinadas ao processo de beneficiamento nas serrarias. Nessa fase, ocorre o desdobramento dos blocos em chapas e, a seguir, estas chapas são conduzidas para as etapas de levigamento, polimento e lustração, de acordo com a especificação do mercado. Após as chapas estarem devidamente preparadas, são transportadas para as marmorarias, onde são realizados os processos de corte e acabamento das peças. Durante todos esses processos, é gerada uma lama, composta por resíduos provenientes de rochas ornamentais e água. Com o intuito de reduzir os custos das marmorarias e os impactos negativos causados pelo descarte desse material, além de encontrar uma alternativa sustentável e útil para a sociedade, este trabalho tem como objetivo aproveitar os resíduos finos para fabricar um ladrilho hidráulico piso tátil, do tipo alerta e direcional, que tem como finalidade auxiliar deficientes visuais a se orientarem em sua locomoção.
\end{abstract}

Palavras-chave: Ladrilho Hidráulico Piso Tátil, Resíduos Finos, Rochas Ornamentais, Sustentabilidade.

Ornamental rocks are classified in granites and marbles, usually extracted from quarries in the form of blocks, and are intended for subsequent processing process, which begins in sawmills. At this stage, blocks are cut into slabs, which will later be treated by levigation, polishing or lustration, according to market specifications. When the slabs are properly prepared, they are transported to the marble industry, where the cutting and finishing of parts are made. Mud are generated during all these processes, and it consists of waste from ornamental stone and water. In order to reduce the marble industry costs and the negative impacts caused by the disposal of this material, and to find a sustainable alternative that is useful to society, this paper has the objective to use the fine waste to manufacture hydraulic tile tactile floor, both the warning type as the directional type, which aims to help the visually impaired to orientate themselves. Keywords: Fine Waste, Ornamental Rock, Sustainability, Tile Hydraulic Tactile Floor. 


\section{INTRODUÇÃO}

O presente estudo tem como escopo a análise da utilização de resíduos finos provenientes de rochas ornamentais para a fabricação do ladrilho hidráulico piso tátil. De acordo com a NBR 9457 (1986), o ladrilho hidráulico é definido como "placa de concreto de alta resistência ao desgaste, para acabamento de paredes e pisos internos e externos, colorido ou não, de formato quadrado, retangular ou outra forma geométrica definida". Esse revestimento hidráulico recebe esse nome devido ao seu processo de fabricação, no qual se utiliza um aglomerante hidráulico que na presença de água adquire resistência, portanto, não envolvendo processos de queima.

Segundo Marques (2010), o processo de fabricação do ladrilho hidráulico piso tátil envolve duas rotas distintas. A primeira, consiste na adição de três camadas, sendo uma camada superior, uma intermediária e uma inferior. Os materiais utilizados nessas camadas são, respectivamente, cimento, pigmento (cor), areia e água. Já o segundo tipo, consiste de uma camada única composta por cimento, areia, brita e água, que são misturados e adicionados em um prato molde que dá forma à peça.

A rocha ornamental, de acordo com Rodrigues et al (2009), é um agregado sólido natural que, depois de extraído, passa por um processo de beneficiamento e, posteriormente, o produto final é utilizado nos ramos da construção civil e da arquitetura, entre outros. As principais rochas que são utilizadas pelo setor de rochas ornamentais são granito, mármore, gnaisse e ardósia.

$\mathrm{Na}$ indústria de rochas ornamentais, a classificação petrográfica das rochas não é seguida à risca. Segundo Larizzatti et al (2005), comercialmente, o termo "granito" abrange, além dos granitos propriamente ditos, sienitos, basaltos, gabros e outros. O mesmo ocorre com os mármores que podem conter tipologias que não são metamórficas, tais como brechas, calcários e outros. Além dessas rochas, são utilizados também o quartzito, o arenito, o serpentinito e outros tipos.

Os resíduos finos de rocha ornamental são gerados durante o processo de corte, tanto nas serrarias, quanto nas marmorarias.

Dados do SEBRAE (1999) apontam que nas marmorarias, onde se realiza a etapa final do processo de produção de rocha ornamental, são executados todos os trabalhos destinados ao mercado consumidor, tais como pias, pisos, bancadas, escadas e peitoris.

No Brasil, o setor de rochas ornamentais é uma forte atividade industrial e vem crescendo nos últimos anos, ocupando uma posição de destaque no cenário internacional, com a $4^{\mathrm{a}}$ posição no ranking mundial em 2013 (DNPM, 2014). O fortalecimento interno da atividade está diretamente ligado ao aumento da população e consequentemente ao crescimento do ramo da construção civil. Por outro lado, com esse crescimento, aumenta também a produção de resíduos, o que gera preocupação ambiental quanto à sua correta destinação.

Diante das atuais exigências ambientais e do alto índice de geração de finos na atividade estudada, este trabalho propôs o aproveitamento desses resíduos para a fabricação de ladrilho hidráulico piso tátil, que é um piso com textura em alto relevo, utilizado principalmente em calçadas, e tem por finalidade auxiliar deficientes visuais a se orientarem em sua locomoção.

Desse modo, o objetivo do estudo consiste em aproveitar os resíduos finos gerados no processo de beneficiamento de rochas ornamentais, em marmorarias, para fabricar o 
ladrilho hidráulico piso tátil. Para isso, é necessário determinar as características físicas desse tipo de rejeito e a qualidade do ladrilho hidráulico fabricado com o uso do resíduo gerado no beneficiamento de rochas ornamentais.

\section{METODOLOGIA}

Este estudo caracteriza-se como uma pesquisa exploratória e aplicada, pois envolve a aplicação prática para a solução de um problema, visto que a produção de finos provenientes de rochas ornamentais nas marmorarias gera impacto ambiental quando o rejeito é descartado de maneira incorreta. Portanto, é importante destinar esses finos para uma utilização adequada.

De acordo com Gil (2002), a pesquisa exploratória visa maior conhecimento do problema e tem como intuito construir hipóteses para o mesmo. A hipótese apresentada neste estudo é a utilização desses finos para a fabricação de ladrilho hidráulico piso tátil.

A pesquisa bibliográfica é o meio mais adequado quando se deseja obter informações científicas, pois este tipo de pesquisa é desenvolvido a partir de livros ou artigos já elaborados (GIL, 2002). Portanto, permite ao investigador uma cobertura mais ampla sobre o assunto. Tem como objetivo também, a análise do tema sob um novo foco, o que possibilita gerar novas conclusões.

Este trabalho também foi baseado em uma pesquisa experimental, uma vez que este tipo de pesquisa permite selecionar variáveis que podem influenciar o objeto de estudo (GIL, 2002). Portanto, no caso da fabricação e utilização do ladrilho hidráulico piso tátil, este tipo de pesquisa permite que a hipótese seja testada.

Devido à escassez de conteúdo, o estudo da dosagem dos resíduos na fabricação do ladrilho hidráulico piso tátil baseou-se principalmente em artigos científicos, a fim de garantir um produto de qualidade e que atendesse às normas regulamentadoras.

Na pesquisa quantitativa, os dados são quantificáveis, ou seja, são expressos em números e podem ser classificados (SILVA, 2004). Alguns testes foram realizados nos resíduos e no ladrilho fabricado, e os resultados foram obtidos através de números, o que permitiu a análise e a interpretação dos dados.

Inicialmente, foi realizada a coleta dos resíduos em uma marmoraria da cidade de João Monlevade. A seguir, foi feita a caracterização do rejeito, o que deu a esta pesquisa uma abordagem também qualitativa, passando o material por alguns procedimentos que levantaram as propriedades físicas do resíduo.

\section{MATERIAL E PROCEDIMENTOS}

Os principais materiais utilizados na pesquisa, assim como as atividades realizadas para a caracterização física do resíduo para a confecção do corpo de prova e para fabricação do ladrilho hidráulico piso tátil serão descritos a seguir.

\subsection{Material utilizado para confecção dos corpos de prova e dos ladrilhos hidráulicos piso tátil}

A areia fina utilizada para a confecção dos corpos de prova foi fornecida pelo laboratório da Faculdade de Engenharia da Universidade de Minas Gerais, localizada na 
cidade de João Monlevade - MG, na faixa granulométrica de -50 a $+100 \#$ (Mesh), ou seja, de $0,30 \mathrm{~mm}$ a $0,15 \mathrm{~mm}$ (milímetros).

O cimento utilizado foi o Cauê CPIII-32-RS, adquirido em um estabelecimento comercial, na cidade de Barão de Cocais - MG.

A brita utilizada foi do tipo $\mathrm{n}^{\circ} 0$ (zero), cuja faixa granulométrica está entre 4,8 $\mathrm{mm}$ e 12,5 mm. Este material foi adquirido em um depósito de brita localizado na região de Barão de Cocais - MG.

O resíduo fino proveniente de rocha ornamental foi fornecido pela Marmoraria Pedra Forte - Sion, localizada na cidade de João Monlevade - MG. Este material foi coletado em um tanque de sedimentação da máquina de corte de granito e mármore.

\subsection{Caracterização do resíduo e dos corpos de prova}

Para a determinação das características físicas do resíduo e dos corpos de prova, o material foi submetido a diversos ensaios que serão descritos sequencialmente.

\subsubsection{Picnometria}

Este ensaio teve como objetivo determinar a massa específica $\left(\mathrm{kg} / \mathrm{m}^{3}\right)$ do resíduo do presente estudo. Conforme a NBR NM 52 (2002) Massa específica, massa específica aparente e absorção do agregado miúdo, a "massa específica é a relação entre a massa do agregado seco e seu volume, sem considerar os poros permeáveis à água". O material foi coletado no tanque de sedimentação da marmoraria citada e, posteriormente, disposto em um recipiente plástico e exposto ao sol por alguns dias para a secagem natural.

Após a secagem, esse material foi levado para o laboratório da UEMG. A seguir, o resíduo foi colocado na estufa para a retirada da umidade. Em seguida, foi realizada a homogeneização e o quarteamento de parte do resíduo através do método de pilha cônica. Após o quarteamento, foram obtidas quatro alíquotas homogêneas. Uma dessas alíquotas foi destinada à realização do teste de picnometria, seguindo os seguintes passos:

- Pesou-se o picnômetro vazio (frasco + tampa) na balança de precisão e o resultado foi registrado;

- Preencheu-se o picnômetro com a amostra de resíduo até a linha marcada (50 ml) no picnômetro com a ajuda de um funil;

- Pesou-se novamente (picnômetro + amostra) e o resultado foi registrado;

- Adicionou-se água ao picnômetro para preencher todos os espaços vazios e até o picnômetro estar completamente preenchido;

- Secou-se a parte externa do picnômetro;

- Verificou-se a presença de ar dentro do picnômetro e, através de leves batidas, o mesmo foi retirado;

- Colocou-se a tampa e adicionou-se água até completar o canal capilar;

- Secou-se a parte externa;

- Pesou-se o picnômetro + amostra + água e anotou-se o resultado; 
- Retirou-se o material presente dentro do picnômetro;

- Adicionou-se água até preenchê-lo por completo;

- Colocou-se a tampa e adicionou-se água até completar o canal capilar;

- Secou-se a parte externa;

- Pesou-se o picnômetro somente com água.

Durante o ensaio, foram realizados três procedimentos de picnometria com picnômetros diferentes, para garantir uma melhor precisão dos resultados. Após a coleta dos valores obtidos, utilizou-se a Equação (1) para realizar os cálculos necessários na determinação da massa específica do resíduo (densidade).

$$
d s=\frac{P_{2}-P_{1}}{\left(P_{4}+P_{2}\right)-\left(P_{1}+P_{3}\right)}
$$

Onde:

$d s$ : densidade dos sólidos;

$P_{1}$ : massa do picômetro;

$P_{2}$ : massa do picômetro + amostra;

$P_{3}$ : massa do picômetro + amostra + água;

$P_{4}$ :massa do picômetro + água.

\subsubsection{Peneiramento}

O ensaio de peneiramento teve como objetivo classificar o material de acordo com o tamanho das partículas presentes na amostra, portanto, este ensaio teve como intuito conhecer a distribuição granulométrica do pó de rocha. Foi utilizada uma das alíquotas provenientes da homogeneização e quarteamento da amostra para a realização desse ensaio.

O tipo de peneiramento aplicado foi a seco. De acordo com Sampaio (2007), no peneiramento a seco as partículas são submetidas à superfície da tela da peneira, onde se encontram as aberturas, e durante o processo de vibração, as partículas rolam umas sobre as outras de modo que todas essas partículas tentam encontrar a abertura da peneira, permitindo que as partículas menores passem pela abertura e as maiores fiquem retidas.

O ensaio foi realizado conforme a NBR NM 248 (2003) - Composição granulométrica dos resultados c que descreve o procedimento a ser seguido para o referido teste. Portanto, antes de se realizar o ensaio, a amostra foi secada em estufa para se evitar o efeito da umidade durante o peneiramento, pois, na amostra úmida, as partículas tendem a se aglomerar diminuindo assim a eficácia dos resultados.

Para a realização do teste, foram realizados os seguintes procedimentos:

- Pesou-se a amostra inicial na balança;

- Definiram-se quais peneiras seriam utilizadas para a realização do teste; 
- As peneiras escolhidas foram: 50\# (0,300 mm), 100\# (0,150 mm), 200\# (0,075 mm), $325 \#(0,044 \mathrm{~mm})$ e fundo (passante da peneira anterior);

- Encaixaram-se as peneiras na ordem crescente da base para o topo com o fundo na base;

- Encaixaram-se as peneiras no peneirador vibratório;

- Dispôs-se a amostra sobre a peneira superior;

- Colocou-se a tampa;

- Ligou-se o peneirador vibratório;

- Aguardou-se 15 minutos;

- Desligou-se o equipamento;

- Retiraram-se as peneiras;

- Colocou-se o material retido de cada peneira, um por vez, em uma bandeja identificada e com peso conhecido;

- Com auxílio de uma escova, escovou-se a tela de cada peneira dos dois lados para a retirada de material retido na tela. Pesou-se o retido de cada peneira e do fundo.

\subsubsection{Confecção dos corpos de prova}

Os ladrilhos hidráulicos piso tátil foram moldados através de uma forma, com o objetivo de verificar qual a melhor fração para a mistura, utilizando o resíduo proveniente de rocha ornamental, combinando com os materiais que são utilizados na preparação da massa (cimento, areia e brita $\mathrm{n}^{\circ} 0$ ). Foram preparados seis corpos de prova, utilizando diferentes frações dos materiais, conforme demonstrado na Tabela 1.

Tabela 1 - Composição dos corpos de prova.

\begin{tabular}{cccccccc}
\hline $\begin{array}{c}\text { Corpo de } \\
\text { prova }\end{array}$ & Cimento & $\begin{array}{c}\text { Pó de } \\
\text { rocha }\end{array}$ & Areia & Brita n $\mathbf{~}^{\mathbf{0}}$ & Água & $\begin{array}{c}\mathbf{N}^{\circ} \text { de corpos de } \\
\text { prova }\end{array}$ & $\begin{array}{c}\text { \% de pó de } \\
\text { rocha } \\
\text { contido }\end{array}$ \\
\hline $\mathbf{1}$ & 1,0 & 1,0 & 1,0 & 0,0 & 1,0 & 6 & 33,3 \\
$\mathbf{2}$ & 1,0 & 2,0 & 1,0 & 0,0 & 1,5 & 6 & 50,0 \\
$\mathbf{3}$ & 2,0 & 1,0 & 1,0 & 0,0 & 1,5 & 6 & 25,0 \\
$\mathbf{4}$ & 3,0 & 1,0 & 1,0 & 0,0 & 1,75 & 6 & 20,0 \\
$\mathbf{5}$ & 2,0 & 2,0 & 0,0 & 1,0 & 1,5 & 6 & 40,0 \\
\hline $\mathbf{6}$ & 2,0 & 1,0 & 0,0 & 1,0 & 1,0 & 6 & 25,0 \\
\hline
\end{tabular}

Fonte: Pesquisa Aplicada (2017).

Para a fabricação desses corpos de prova foi utilizado um copo graduado em $50 \mathrm{ml}$, como referência para determinar a porção de cada material a ser adicionada à mistura. 
Primeiramente, com o auxílio do copo graduado, a porção de cada material foi colocada em um recipiente. Em seguida, esses materiais foram misturados com uma espátula, até se tornar uma mistura homogênea.

Após a homogeneização, adicionou-se água à mistura até se atingir uma consistência pastosa. Por fim, o material foi colocado nos moldes do ladrilho hidráulico piso tátil dos tipos alerta e direcional, em local sombreado e plano, conforme ilustrado pelas Figuras 1 e 2 .

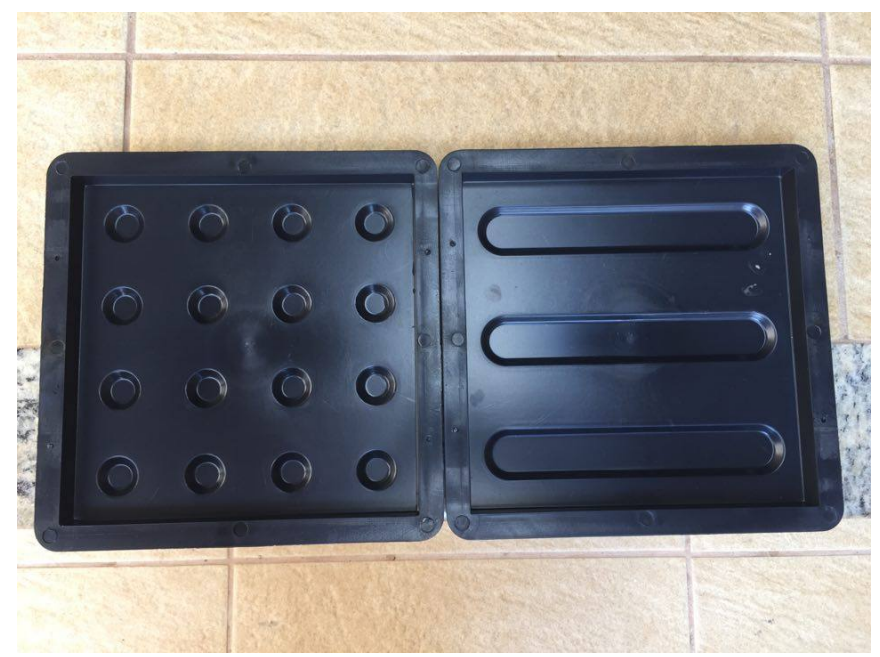

Figura 1 - Molde do ladrilho hidráulico piso tátil do tipo alerta (esquerda) e direcional (direita).

Fonte: Acervo pessoal (2016).

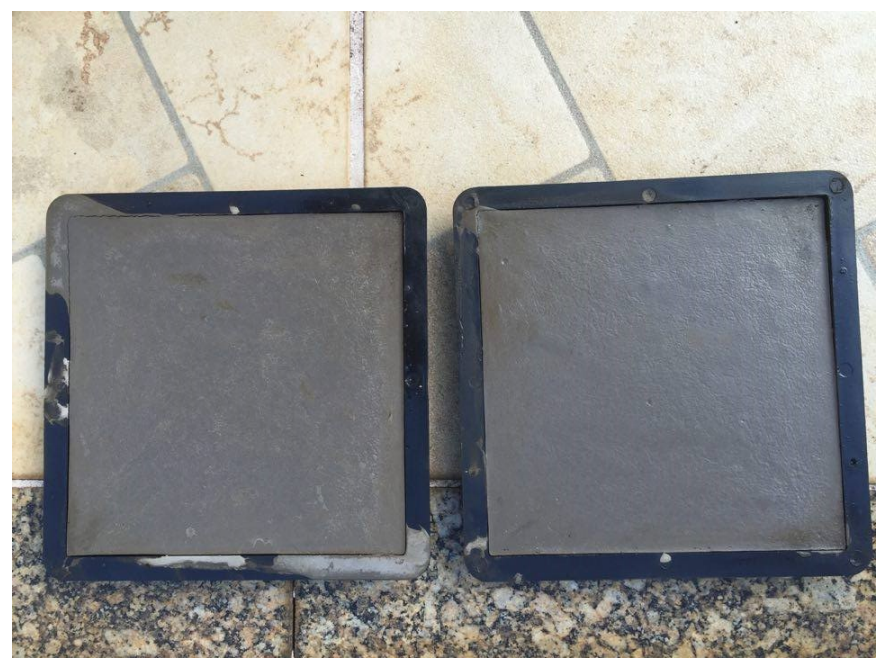

Figura 2 - Molde do ladrilho hidráulico com a mistura. Fonte: Acervo pessoal (2016).

Após 24 horas, os ladrilhos foram desenformados do molde e destinados ao processo de cura. Para realizar o processo de cura, seguiu-se o procedimento observado e anotado durante uma visita técnica a uma fábrica de ladrilhos da região.

Os ladrilhos, primeiramente, foram deixados secando em local sombreado e à 
temperatura ambiente, durante 24 horas. Após esse procedimento, os mesmos foram imersos em água durante 5 minutos e em seguida retirados e colocados ao sol para a secagem, durante três dias (72 horas). Feito isso, o ladrilho hidráulico estava pronto para ser utilizado. Dessa maneira, o procedimento para a fabricação do ladrilho hidráulico piso tátil dura cerca de cinco dias para deixar o produto pronto para uso.

\subsubsection{Ensaio de determinação da absorção de água por imersão}

O ensaio de absorção de água foi feito com base na norma NBR 9778 - Argamassa e concreto endurecidos - Determinação da absorção de água por imersão - Índice de vazios e massa específica (ABNT, 2005).

Primeiramente, os corpos foram colocados em estufa à temperatura de $105( \pm 5)$ ${ }^{\circ} \mathrm{C}$, durante um período de 72 horas (três dias).

Em seguida, após ocorrer a secagem do material, os corpos de prova foram retirados e deixados resfriar à temperatura ambiente $23( \pm 2)^{\circ} \mathrm{C}$. Posteriormente, para a determinação das massas (Ms), os corpos de prova foram pesados e, então, colocados em um recipiente apropriado, no qual foi adicionada água até preencher $1 / 3$ do volume dos corpos de prova. Esse procedimento durou 4 horas.

Depois desse procedimento, adicionou-se água até preencher $2 / 3$ do volume dos corpos de prova, durante as 4 horas subsequentes. Por fim, foi preenchido todo o volume, ou seja, os corpos de prova foram completamente imersos em água e deixados em repouso durante 64 horas.

Em seguida, para determinar a massa saturada (Msat), os corpos de prova foram enxugados com toalha absorvente e, então, foram pesados novamente.

O percentual do índice de absorção de água dos corpos de prova foi obtido através da média dos resultados calculados com base na Equação (2).

$$
\text { Absorção }=\frac{M s a t-M s}{M s} x
$$

Onde:

Msat: massa do corpo de prova saturado;

$M s$ : massa do corpo de prova seco em estufa.

\subsubsection{Ensaio de alterabilidade}

Para realizar esse ensaio, as seis variações de corpos de prova produzidos foram submetidas a dois testes. No primeiro, os corpos de prova foram submetidos a variações bruscas de temperatura (de $120{ }^{\circ} \mathrm{C}$ para $20{ }^{\circ} \mathrm{C}$ ). Para tanto, os mesmos foram aquecidos em estufa durante dois dias com temperatura de $120^{\circ} \mathrm{C}$.

Após sua retirada (sem deixar resfriar), os corpos de prova foram colocados em um recipiente (balde) com água (temperatura aproximada de $20^{\circ} \mathrm{C}$ ), ou seja, foram resfriados bruscamente para verificar se houve alguma alteração em sua estrutura.

Os corpos de prova foram deixados imersos por 10 minutos e, após esse tempo, retirados e colocados sobre uma bancada para verificar se houve alguma alteração. Esse procedimento foi realizado no laboratório da Faculdade de Engenharia da Universidade do Estado de Minas Gerais, localizado na cidade de João Monlevade - MG. 
O segundo teste teve como objetivo submeter os ladrilhos ao atrito, ou seja, os ladrilhos hidráulicos piso tátil foram impostos a uma situação real de utilização no dia a dia. Para isso, os corpos de prova foram assentados em uma calçada com tráfego médio de 100 pessoas por hora, no bairro Vila São Geraldo, localizado na cidade de Barão de Cocais - MG, conforme ilustram as Figuras 3 e 4.

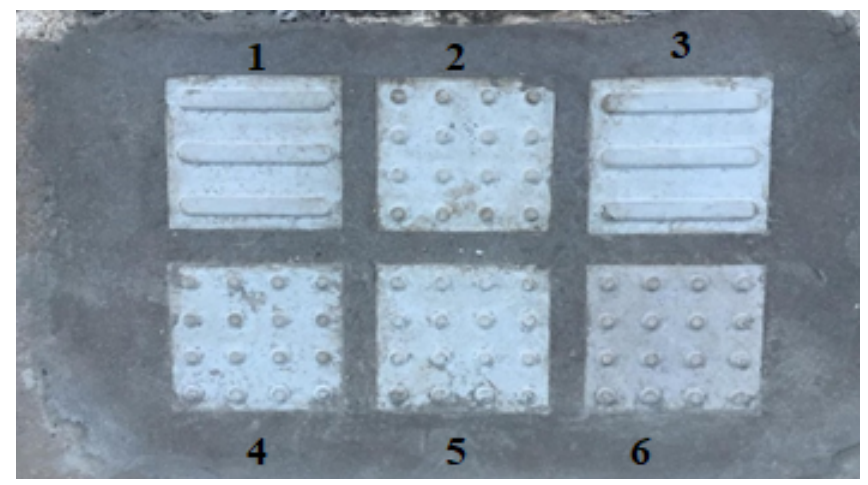

Figura 3 - Ladrilhos assentados em calçada. Fonte: Acervo pessoal (2016).

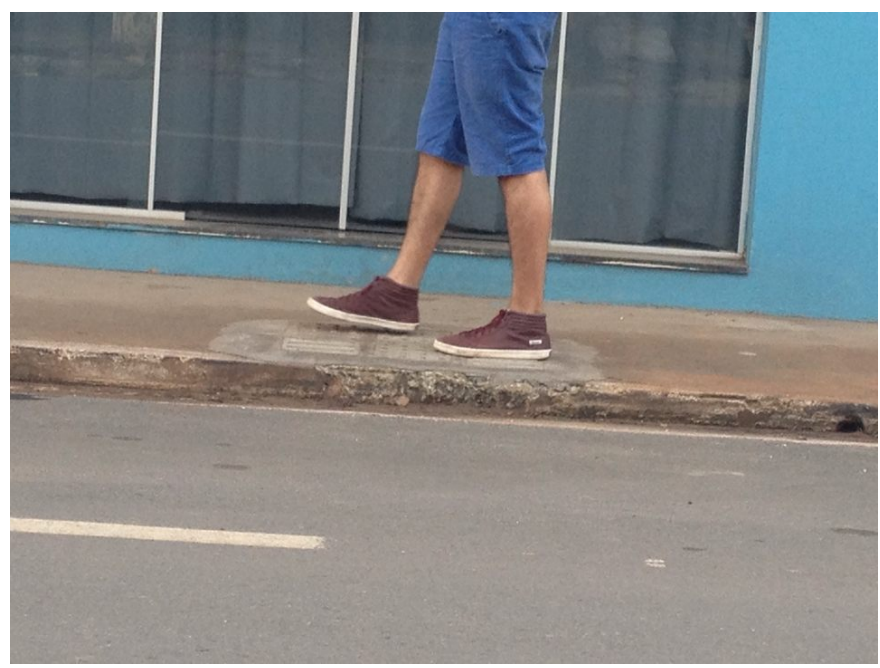

Figura 4-Ladrilhos hidráulicos submetidos ao tráfego de pessoas sobre a calçada. Fonte: Acervo pessoal (2016).

Posteriormente, foi feita uma análise visual dos ladrilhos hidráulicos piso tátil no local para observar a ocorrência de algum desgaste ou outra alteração na superfície dos mesmos, resultados que serão descritos na sequência.

\section{DISCUSSÃO DOS RESULTADOS}

Os resultados obtidos com os ensaios realizados, bem como as análises dos mesmos, serão descritos a seguir. 


\subsection{Ensaio de picnometria}

Segundo a Norma NBR 7211 (2009), em relação à origem, os materiais podem ser classificados como naturais ou artificiais. $\mathrm{O}$ material da presente pesquisa é do tipo artificial, pois é um material obtido através de processos industriais, visto que os materiais classificados como naturais são aqueles encontrados na natureza e que geralmente requerem um processo simples de lavagem ou seleção. Em relação à massa específica, os materiais podem ser classificados como:

- Leves - massa específica inferior a $2000 \mathrm{Kg} / \mathrm{m}^{3}$;

- Normais - massa específica entre $2000 \mathrm{Kg} / \mathrm{m}^{3}$ e $3000 \mathrm{Kg} / \mathrm{m}^{3}$;

- Pesados - massa específica superior a $3000 \mathrm{Kg} / \mathrm{m}^{3}$.

Através do ensaio de picnometria, foi calculada a massa específica do resíduo fino para os três ensaios realizados. Posteriormente, o valor obtido em cada ensaio foi somado e divido por três, ou seja, foi feita a média dos resultados. O valor encontrado foi de 2532,45 $\mathrm{Kg} / \mathrm{m}^{3}$. Com base nesse resultado, pode-se classificar o resíduo como "normal". Esse valor está diretamente relacionado com o peso do material, ou seja, quanto maior, mais pesado será o material.

\subsection{Ensaio de peneiramento}

O ensaio de peneiramento foi realizado de acordo com a Norma NBR NM 248 (2003) Composição granulométrica dos resultados, que determina que o relatório do ensaio dever conter a porcentagem média retida em cada peneira e a porcentagem média retida acumulada em cada peneira.

A Tabela 2 apresenta a faixa granulométrica utilizada no procedimento, a massa retida em cada peneira, bem como a porcentagem de retido simples (obtida pela divisão do valor da massa retida em cada peneira pelo total da soma das massas), o retido acumulado (soma das porcentagens do retido simples) e o passante acumulado (obtido através da subtração do valor 100 pelo valor registrado na coluna de passante acumulado).

Tabela 2 - Peneiramento.

Faixa Granulométrica

Massa inicial $=500 \mathrm{~g}$

\begin{tabular}{|c|c|c|c|c|c|}
\hline \multicolumn{2}{|c|}{ ralxa Granulometrica } & \multicolumn{4}{|c|}{ Ivrassa Imictal - 500 g } \\
\hline $\begin{array}{l}\text { Mesh } \\
\text { (\#) }\end{array}$ & $\mathrm{mm}$ & Massa $(g)$ & $\begin{array}{c}\text { Retido Simples } \\
(\%)\end{array}$ & $\begin{array}{c}\text { Retido } \\
\text { Acumulado (\%) }\end{array}$ & $\begin{array}{c}\text { Passante } \\
\text { Acumulado } \\
(\%)\end{array}$ \\
\hline 50 & 0,300 & 30,802 & 6,188 & 6,188 & 93,812 \\
\hline 100 & 0,150 & 18,721 & 3,761 & 9,950 & 90,050 \\
\hline 200 & 0,075 & 89,402 & 17,962 & 27,911 & 72,089 \\
\hline 325 & 0,044 & 293,440 & 58,955 & 86,867 & 13,133 \\
\hline Fundo & $-0,044$ & 65,370 & 13,133 & 100,000 & 0,000 \\
\hline \multicolumn{2}{|c|}{ Total } & 497,735 & 100,000 & & \\
\hline \multicolumn{2}{|c|}{ Alimentação rec. (g) } & \multicolumn{2}{|c|}{497,735} & & \\
\hline \multicolumn{2}{|c|}{ Perda (g) } & \multicolumn{2}{|c|}{2,265} & & \\
\hline \multicolumn{2}{|c|}{ Erro (\%) } & \multicolumn{2}{|c|}{0,453} & & \\
\hline
\end{tabular}

Fonte: Pesquisa Aplicada (2017). 
Com base nos dados obtidos na Tabela 2, plotou-se o Gráfico 1, em escala logarítmica no eixo das abscissas, representando o passante acumulado em função da abertura das peneiras. Portanto, com base nos dados apresentados, 90,050\% da amostra é considerada ultrafina (menor que $0,15 \mathrm{~mm}$ ) e passante na abertura de $0,15 \mathrm{~mm}$, e os outros $9,950 \%$ da amostra é considerada fina (entre 6,35 $\mathrm{mm}$ e 0,15 mm).

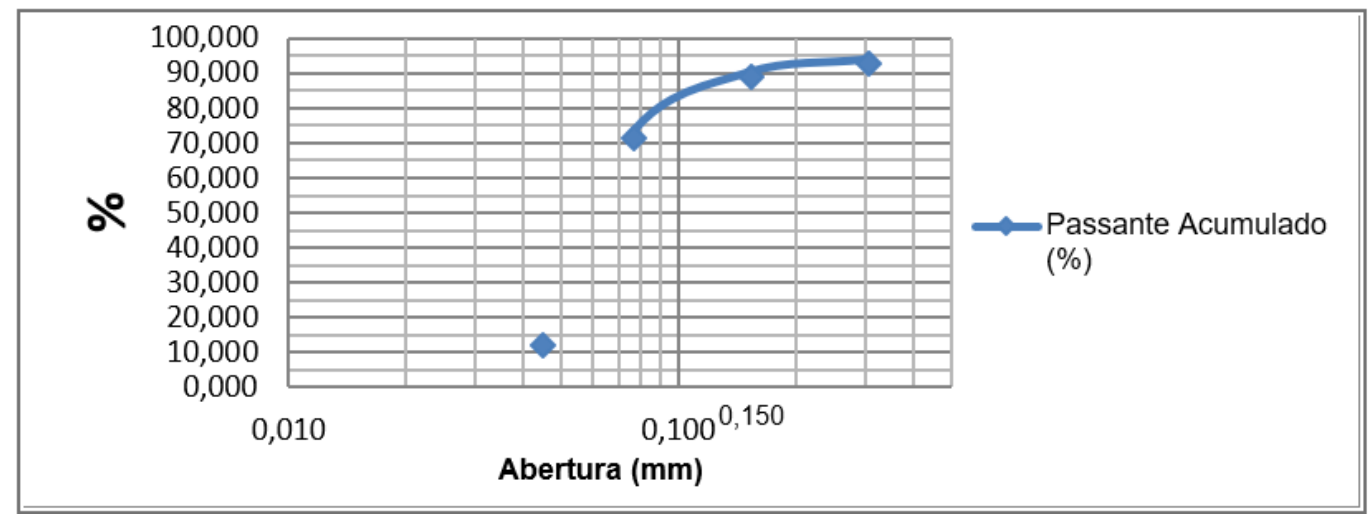

Gráfico 1 - Passante acumulado.

Fonte: Pesquisa Aplicada (2017).

\subsection{Ensaio de determinação da absorção de água por imersão}

Com base na norma utilizada NBR 9778 (2005) Argamassa e concreto endurecido - Determinação da absorção de água por imersão - Índice de vazios e massa específica, foi calculada a porcentagem de absorção de água de cada corpo de prova. A Tabela 3 apresenta a porcentagem de absorção de água de cada ladrilho hidráulico piso tátil em relação às massas seca e saturada.

O corpo de prova que apresentou maior índice de absorção de água foi aquele que possui mais cimento em sua composição, como pode ser observado o resultado do corpo de prova 4, com 32,96\% de água absorvido. Em contrapartida, o corpo de prova que apresentou menor absorção de água foi o que mais possui pó de rocha em sua composição, conforme mostra o resultado do corpo de prova de número 2, com 16,08\% de absorção de água.

Tabela 3 - Teste de absorção de água.

\begin{tabular}{cccc}
\hline Corpo de prova & $\begin{array}{c}\text { Massa do corpo } \\
\text { de prova seco } \\
\mathbf{( g )}\end{array}$ & $\begin{array}{c}\text { Massa do corpo } \\
\text { de prova } \\
\text { saturado }(\mathbf{g})\end{array}$ & $\begin{array}{c}\text { índice de absorção } \\
\text { de água (\%) }\end{array}$ \\
\hline $\mathbf{1}$ & 797,2 & 1017,2 & 27,60 \\
$\mathbf{2}$ & 886,0 & 1028,5 & 16,08 \\
$\mathbf{3}$ & 870,6 & 1096,1 & 25,90 \\
$\mathbf{4}$ & 823,4 & 1094,8 & 32,96 \\
$\mathbf{5}$ & 929,3 & 1136,7 & 22,31 \\
\hline
\end{tabular}

Fonte: Pesquisa Aplicada (2017). 
O Gráfico 2 mostra a comparação do índice de absorção de água com as porcentagens de cimento e pó de rocha contido em cada corpo de prova.

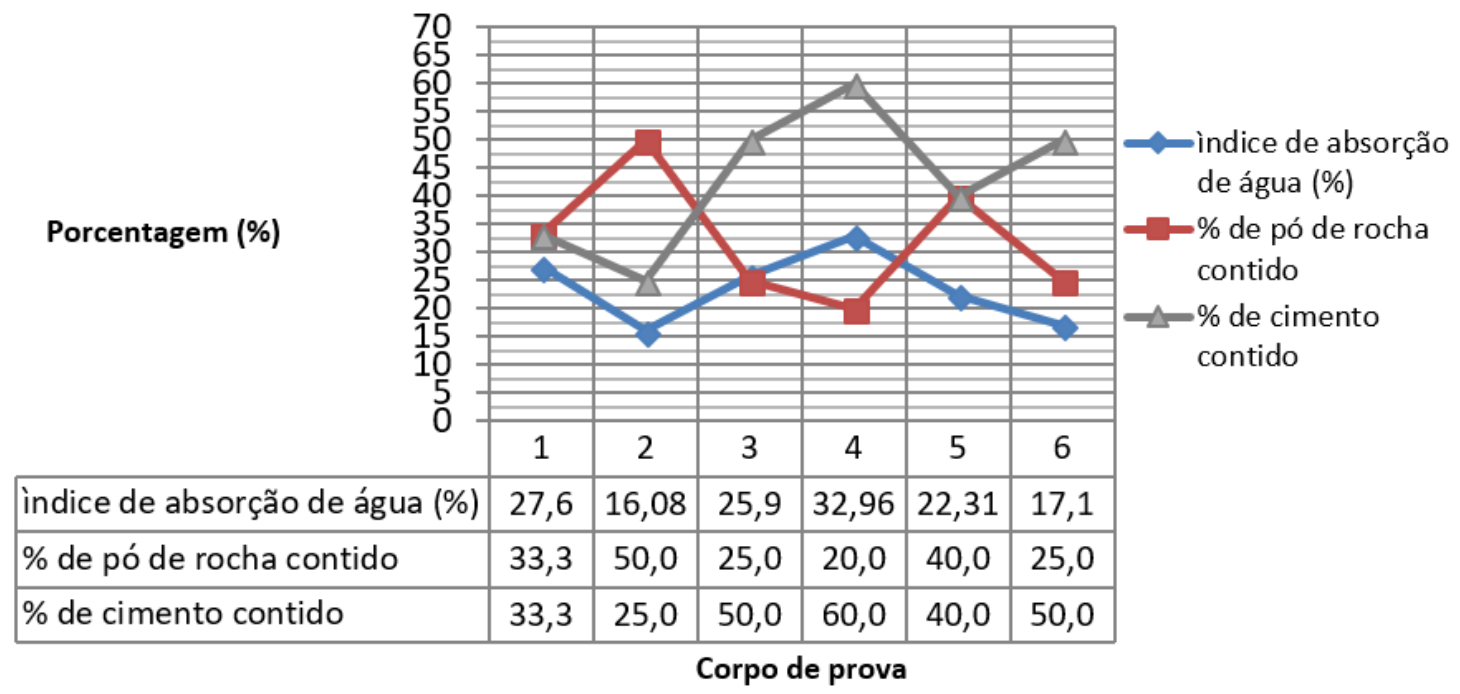

Gráfico 2 - Comparação entre o índice de absorção de água com as porcentagens de pó de roch a e cimento.

Fonte: Pesquisa Aplicada (2017).

Com base no gráfico apresentado, é possível observar que o índice de absorção de água correlaciona à medida que aumentam e diminuem as porcentagens de pó de rocha e de cimento na composição de cada corpo de prova. Portanto, foi constatado que com o aumento da porcentagem de pó de rocha diminuiu-se também o índice de absorção de água. Uma razão para isto é o fato de que a característica granulométrica do pó de rocha preenche melhor os espaços vazios dentro do ladrilho hidráulico, o que reduz o efeito de infiltração de água. Isso demonstra a viabilidade da adição do resíduo.

Segundo a norma NBR 9457 (1986) o índice de absorção de água para ladrilhos hidráulicos prensados é descrito conforme mostra a Tabela 4.

Tabela 4 - Limite da norma para ladrilho hidráulico prensado.

\begin{tabular}{llc}
\hline Propriedades & Ensaio & $\begin{array}{c}\text { Limites: NBR } \\
\mathbf{9 4 5 7 : 1 9 8 6}\end{array}$ \\
\hline $\begin{array}{l}\text { Absorção de } \\
\text { água }\end{array}$ & NBR 13818: 1997 Anexo B & Máximo de 8\% \\
\hline
\end{tabular}

Fonte: Pesquisa Aplicada (2017).

O ladrilho hidráulico prensado apresenta esse limite máximo de $8 \%$ pois, depois de prensado, os espaços vazios presentes no interior da peça são reduzidos consideravelmente, o que explica os valores obtidos no experimento, pois o mesmo não foi prensado.

Portanto, um fator que pode reduzir o índice de absorção de água desses ladrilhos é a pintura dos mesmos. Uma vez pintados os ladrilhos, a tinta presente na superfície tem por função, além de dar cor à peça, criar uma película protetora que reduz a infiltração de água através da mesma. 


\subsection{Ensaio de alterabilidade}

No primeiro ensaio realizado (variação de temperatura), os ladrilhos hidráulicos piso tátil não apresentaram nenhuma anomalia (trincas ou quebras), diante da variação de temperatura (de $120^{\circ} \mathrm{C}$ para $20^{\circ} \mathrm{C}$ ) imposta sobre eles. A Figura 5 ilustra os ladrilhos sem nenhuma alteração.

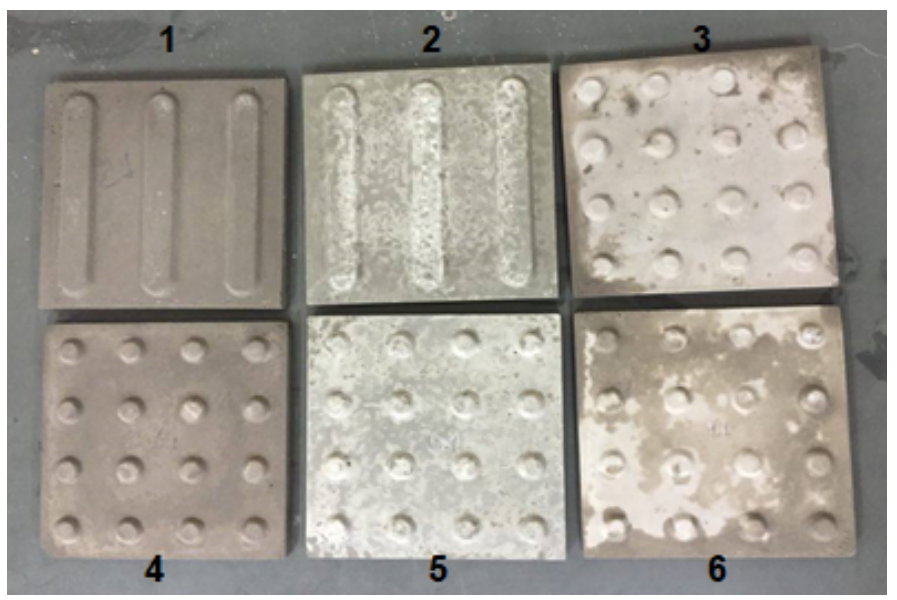

Figura 5 - Ladrilhos hidráulicos na bancada para análise virtual. Fonte: Acervo pessoal (2016)

No segundo teste (situação real de como são aplicados), após 30 dias, foi observado no local, que os ladrilhos hidráulicos sofreram arranhões devido ao tráfego intenso de pessoas. No ladrilho hidráulico $\mathrm{n}^{\mathrm{o}} 2$, foi observado uma trinca na parte central da superfície do mesmo, mas não houve desgastes ou quebras, portanto não comprometeu a sua utilização, e permaneceu em condições adequadas para o tráfego de deficientes visuais, conforme a Figura 6.

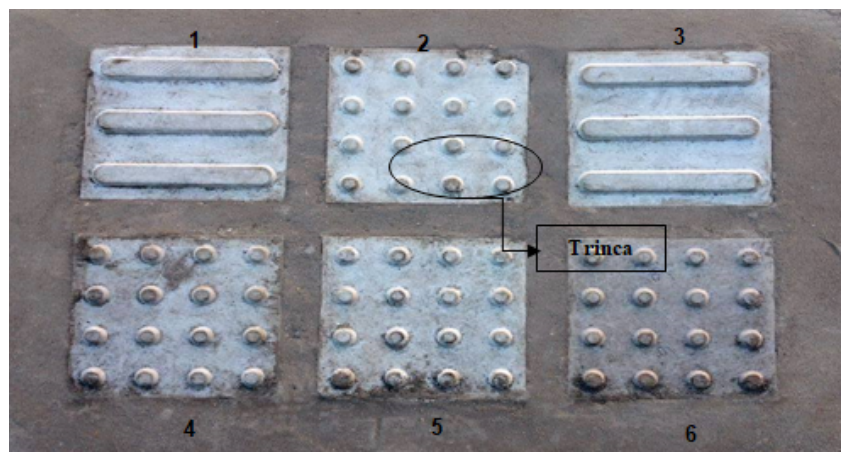

Figura 6 - Ladrilhos hidráulicos na calçada após trinta dias.

Fonte: Acervo pessoal (2016).

Os demais ladrilhos não apresentaram trincas ou quebras em sua estrutura, somente arranhões causados pelo atrito devido ao tráfego de pessoas no local. Portanto, com base na análise visual realizada nesse período de tempo, o ladrilho hidráulico piso tátil fabricado com o resíduo fino de rocha ornamental mostrou-se eficaz para utilização em uma situação real do dia a dia, exercendo sua função de orientar deficientes visuais a se locomoverem de forma segura. 


\section{CONSIDERAÇÕES FINAIS}

Com base nos resultados obtidos, pode-se afirmar que a adição de resíduos finos provenientes de rocha ornamental gerados no corte das placas de rochas nas marmorarias mostrou-se tecnicamente viável ao ser aplicado na fabricação do ladrilho hidráulico piso tátil, atingindo os objetivos propostos pela pesquisa.

Apesar dos avanços tecnológicos, a geração de resíduos finos sempre estará presente no processo produtivo das marmorarias. Dessa forma, é de extrema importância destinar este material para um aproveitamento adequado. O seu aproveitamento contribui para evitar gastos com o seu descarte, reduzindo o impacto ambiental causado por esse segmento industrial, e contribuindo também para o aumento da vida útil dos aterros municipais de materiais inertes. Outro benefício importante que pode ser relatado com essa prática é que a adição desses resíduos pode substituir parcialmente as areias, que são agregados naturais não renováveis e que estão cada vez mais escassos.

A pesquisa constatou que a adição do resíduo na fabricação de ladrilhos hidráulicos piso tátil é viável, uma vez que o produto, utilizado em situação real, exerceu sua função e permaneceu intacto durante o período de teste.

O resíduo atua como carga mineral, ou seja, é utilizado como material de enchimento em materiais cimentícios, reduzindo parcialmente a adição de outros materiais que possuem maior valor de custo.

É importante enfatizar que o aproveitamento e a reciclagem do resíduo constituem uma alternativa viável tecnicamente para que o setor de marmoraria seja mais sustentável ambientalmente, reduzindo o volume de material descartado e possível contaminação do solo e cursos d'água.

Outro ponto a destacar é que a alternativa proposta se mostrou relevante no aspecto social, pois o ladrilho hidráulico piso tátil é um produto de grande utilidade para auxiliar os deficientes visuais a se orientarem em seu deslocamento, tornando seu trajeto mais seguro.

\section{REFERÊNCIAS BIBLIOGRÁFICAS}

ASSOCIAÇÃO BRASILEIRA DE NORMAS TÉCNICAS. NBR 9457: Classificação de resíduos sólidos. Rio de Janeiro, 1986.

ASSOCIAÇÃO BRASILEIRA DE NORMAS TÉCNICAS. Norma MERCOSUL. NBR NM 52: Agregado miúdo - Determinação da massa específica e da massa específica aparente. Rio de Janeiro, 2002.

ASSOCIAÇÃO BRASILEIRA DE NORMAS TÉCNICAS. Norma MERCOSUL. NBR NM 248: Determinação da composição granulométrica. Rio de Janeiro, 2003.

ASSOCIAÇÃO BRASILEIRA DE NORMAS TÉCNICAS. NBR 9778: Argamassa e concreto endurecidos - Determinação da absorção de água por imersão - Índice de vazios e massa específica. Rio de Janeiro, 2005. 
ASSOCIAÇÃO BRASILEIRA DE NORMAS TÉCNICAS. NBR 7211: Agregados para concreto: especificação. Rio de Janeiro, 2009.

ASSOCIAÇÃO BRASILEIRA DE NORMAS TÉCNICAS. NBR 9457: Ladrilho hidráulico. Rio de Janeiro, 1986.

DEPARTAMENTO NACIONAL DE PRODUÇÃO MINERAL (DNPM). Rochas ornamentais e de revestimento. Sumário Mineral, 2014.

GIL, A. C. Como elaborar projetos de pesquisa. 4. ed. São Paulo: Atlas S/A, 2002.

LARIZZATTI, J. H. et al. Rochas ornamentais e de revestimento: conceito, tipos e caracterização tecnológica. Curso de especialização em mármores e granitos. Ministério de Ciência e Tecnologia e Centro Tecnológico de Mármore e Granito (CETEMAG). Espírito Santo, 2005.

MARQUES, J. S. Estudo do processo de produção de ladrilhos hidráulicos visando à incorporação de resíduos sólidos. Programa de Pós-Graduação em Engenharia de Edificações e saneamento. Universidade Estadual de Londrina. Londrina, 2012.

RODRIGUES, E. P. et al. Guia de aplicação de rochas em revestimentos - Projeto bula. ABIROCHAS (Associação Brasileira de Rochas Ornamentais). São Paulo, 2009.

SAMPAIO, J. A. Tratamento de minérios - Práticas laboratoriais. Rio de Janeiro: Centro de Tecnologia Mineral (CETEM), 2007.

SEBRAE (Serviço de Apoio às Micro e Pequenas Empresas). Série Perfil de Projetos: marmoraria. Vitória (ES), 1999.

SILVA, C. R. O. Metodologia e organização do projeto de pesquisa. Fortaleza: CEFET - Centro Federal de Educação Tecnológica, 2004. 